\title{
Burden of Herpes Zoster in Adult Patients with Underlying Conditions: Analysis of German Claims Data, 2007-2018
}

\author{
Manuel Batram (D) · Julian Witte (D) - Magdalena Schwarz (D) · Johannes Hain (D) · \\ Bernhard Ultsch (D) - Maren Steinmann (D) - Amit Bhavsar (D) P Peter Wutzler (D) · \\ Carl-Peter Criée - Christiane Hermann (D) - Klaus Wahle (D) - Martin Füchtenbusch • \\ Wolfgang Greiner
}

Received: February 14, 2021 / Accepted: April 15, 2021 / Published online: May 6, 2021

(c) The Author(s) 2021

\section{ABSTRACT}

Introduction: Several chronic underlying conditions (UCs) are known to be risk factors for developing herpes zoster (HZ) and to increase the severity of $\mathrm{HZ}$ and its risk of recurrence. The aim of this study was to investigate the

Supplementary Information The online version contains supplementary material available at https:// doi.org/10.1007/s13555-021-00535-7.

M. Batram $(\bowtie)$

Department for Economics, Bielefeld University, P.O. Box 100131, 33501 Bielefeld, Germany e-mail: mbatram@uni-bielefeld.de

J. Witte $\cdot$ M. Steinmann - W. Greiner

Department for Health Economics and Health Care Management, Bielefeld University,

Universitätsstrasse 25, 33615 Bielefeld, Germany

J. Witte

e-mail: julian.witte@uni-bielefeld.deM. Steinmann

e-mail: maren.steinmann@uni-bielefeld.de

W. Greiner

e-mail: wolfgang.greiner@uni-bielefeld.de

M. Schwarz · J. Hain · B. Ultsch

GSK, Prinzregentenplatz 9, 81675 Munich, Germany

M. Schwarz

e-mail: magdalena.x.schwarz@gsk.com

J. Hain

e-mail: johannes.j.hain@gsk.com incidence and recurrence of $\mathrm{HZ}$ in adult patients with one or multiple UCs.

Methods: A retrospective cohort study based on claims data representing $13 \%$ of the statutory health insurance population from 2007 to 2018 in Germany was performed. Patients aged $\geq 18$ years were included when at least one of the following UCs was diagnosed: asthma, chronic heart failure, chronic obstructive pulmonary disease (COPD), coronary heart disease (CHD), depression, diabetes mellitus type 1 or 2, and rheumatoid arthritis (RA). Exact

\section{B. Ultsch}

e-mail: bernhard.a.ultsch@gsk.com

\author{
A. Bhavsar \\ GSK, Avenue Fleming 20, 1300 Wavre, Belgium \\ e-mail: amit.b.bhavsar@gsk.com \\ P. Wutzler \\ Section of Experimental Virology, Institute of \\ Medical Microbiology, University-Hospital Jena, \\ 07740 Jena, Germany \\ e-mail: Peter.Wutzler@med.uni-jena.de \\ C.-P. Criée \\ Department of Sleep and Respiratory Medicine, \\ Evangelical Hospital Goettingen-Weende, 37120 \\ Bovenden, Germany \\ e-mail: criee@t-online.de

\section{Hermann} \\ Department of Clinical Psychology, Justus-Liebig \\ University Giessen, Otto-Behaghel-Strasse 10F, \\ 35394 Giessen, Germany \\ e-mail: christiane.hermann@psychol.uni-giessen.de
}


matching was used to account for differences in the distribution of age and sex between the case and matched control cohorts. Multi-morbidity was considered in sensitivity analyses by analyzing patients with only one UC.

Results: Patients with asthma, CHD, COPD, depression, and RA had, on average, a 30\% increased risk of developing acute $\mathrm{HZ}$ compared to patients without any UC. RA was found to have the highest odds ratio among these conditions, varying from 1.37 to 1.57 for all age groups. Patients with depression also showed a high risk of developing HZ. Analysis of recurrence indicated that patients with at least one UC in the age groups 18-49 years and 50-59 years had the highest risk for a recurrent HZ. After experiencing a first recurrence, patients, regardless of age group, had a two- to threefold higher risk for a second recurrence.

Conclusion: This study of representative claims data shows a higher HZ incidence and recurrence frequency in patients with UCs. These results provide relevant information for national health care guidelines and disease management programs.

\section{PLAIN LANGUAGE SUMMARY}

Shingles is caused by the reactivation of the chickenpox virus and is characterized by a painful skin rash with blisters, commonly occurring on the trunk. Underlying conditions
(UCs) are conditions that persist for a long time, require ongoing medical attention, and are rarely completely cured (chronic conditions). UCs can increase the severity, the risk, and the frequency of shingles. Here, data from a large German health care insurance provider was used to investigate whether patients with one or more UCs have a higher risk for getting shingles compared to healthy people. In particular, patients with asthma, chronic heart failure, chronic obstructive pulmonary disease, coronary heart disease, depression, diabetes, and rheumatoid arthritis were investigated. The study shows that patients with asthma, coronary heart disease, chronic obstructive pulmonary disease, depression, and rheumatoid arthritis have, on average, a 30\% higher risk of developing shingles, regardless of their age. The risk of developing shingles two or more times is also higher for patients with at least one UC, with those aged 18-59 experiencing an even greater risk. It was found that patients with an UC are more exposed to develop shingles and that younger patients have a higher risk of a recurrent episode. The findings provide important information for the development or adaption of national health care guidelines and shingles vaccination recommendations.

Keywords: Claims data; Incidence; Herpes zoster; Recurrence; Underlying conditions

\section{K. Wahle}

Department of General Medicine, University of Muenster, Domagkstr. 3, 48129 Muenster, Germany e-mail: klaus.wahle@praxiswb.de

M. Füchtenbusch

Diabeteszentrum am Marienplatz, Rindermarkt 3, 80331 Munich, Germany

M. Füchtenbusch

Forschergruppe Diabetes E.V. am Helmholtz

Zentrum München, Ingolstädter Landstraße 1, 85764 Munich-Neuherberg, Germany e-mail: martin.fuechtenbusch@lrz.unimuenchen.de 


\section{Key Summary Points}

\section{Why carry out this study?}

There is a lack of evidence on herpes zoster incidence in patients with an underlying condition and on the frequency of recurrence in the context of German health care.

These data are essential for the development of health care guidelines, disease management programs, and vaccination recommendations.

\section{What was learned from the study?}

Patients with asthma, coronary heart disease, chronic obstructive pulmonary disease, depression, and rheumatoid arthritis have, on average, a $10 \%$ to more than 30\% increased risk of developing acute herpes zoster compared to patients without any underlying condition under study. Among these conditions, rheumatoid arthritis presented the highest risk, varying from 37 to $57 \%$, compared to persons without this condition.

Analysis of recurrence indicated that 18to 59-year-old patients with at least one underlying condition had the highest risk for a new herpes zoster episode. After experiencing a second herpes zoster episode, patients, regardless of age group, had a two- to threefold higher risk for an additional episode of herpes zoster.

\section{DIGITAL FEATURES}

This article is published with digital features, including a summary slide, to facilitate understanding of the article. To view digital features for this article go to https://doi.org/10.6084/ m9.figshare.14414078.

\section{INTRODUCTION}

Herpes zoster (HZ), commonly known as shingles, is a symptomatic reactivation of latent varicella-zoster virus (VZV) which remained in the dorsal root ganglia after the primary infection [1-4]. The clinical presentation of $\mathrm{HZ}$ is characterized by a painful vesicular rash that usually affects one side of the body. The most common complication of $\mathrm{HZ}$ is postherpetic neuralgia (PHN), and the neuropathic pain due to this complication can last several months, or even years, and is often accompanied by significant physical limitations as well as adverse effects on mental health and health-related quality of life (QoL) [5-8].

In Germany, studies based on claims data report HZ incidence rates of 5.8 per 1000 person-years (PY) independent of age [9]. However, $\mathrm{HZ}$ incidence increases with age, particularly from the age of 50 years [10]. The same studies report lower incidence rates ranging from 1.7 cases per 1000 for the age group 0-9 years, to 4.1 cases per 1000 for the age group 40-49 years. Increasing incidence rates have been observed in persons aged 50 years and over, with 6.6 cases per 1000 being noted for persons aged 50-59 years and 12.8 cases per 1000 for those aged 80 years [9]. This age-related increase of $\mathrm{HZ}$ incidence has recently been supported by selfreported pre-test data from the German National Cohort [11]. About 400,000 cases of $\mathrm{HZ}$ occur annually in the German population covered by statutory health insurance (SHI) $[9,12]{ }^{1}$

Aside from age, chronic conditions have been investigated in other countries as risk factors for developing $\mathrm{HZ}$, or as a factor which impacts the severity of HZ. Rheumatoid arthritis (RA), chronic obstructive pulmonary disease (COPD), asthma, diabetes, and depression have been reported as chronic diseases which increase the risk of HZ [13-15]. Additionally, HZ patients with diabetes, cardiovascular diseases, and respiratory diseases as an underlying condition (UC) have been associated with

\footnotetext{
${ }^{1}$ Note that due to the existence of private insurance companies the SHI represents about $87 \%$ of the population living in Germany [12].
} 
significantly higher pain intensity and lower QoL [8]. Patients with diabetes and another UC, such as COPD or heart failure, have been found to have higher $\mathrm{HZ}$ incidence rates compared to healthy subjects $[16,17]$.

In most individuals, HZ occurs only once in a lifetime. However, there is evidence that $\mathrm{HZ}$ can reoccur, especially in those with an UC [18]. Although information on $\mathrm{HZ}$ recurrence is critical for assessing the comprehensive burden of disease caused by HZ, such evidence is limited, as existing studies mostly focus on short followup periods and/or small sample sizes and do not consider the recurrence rates of UCs $[19,20]$. Furthermore, data in the German healthcare context are not yet available. Therefore, the aim of this study was to fill this gap in medical knowledge on the incidence and recurrence of $\mathrm{HZ}$ in patients with an UC in Germany. The results will allow physicians to make evidencebased decisions on vaccination. The interaction between UCs and HZ was also analyzed with respect to excess healthcare resource utilization presented elsewhere.

\section{METHODS}

\section{Study Design}

The study uses a retrospective, matched cohort design and has been conducted in accordance with applicable subject privacy requirements and the guiding principles of the Declaration of Helsinki of 1964. The analysis was based on secondary claims data and, as such, consultation with an ethics committee was not required, in line with the national guidelines "Good Practice Secondary Data Analysis" [21] and the STROSA standard for "Standardized Reporting of Secondary Data Analyses" [22].

Yearly results were computed from 2008 to 2018. Information from 2007 was used to exclude prevalent $\mathrm{HZ}$ cases in the first year under study. In the first analysis, we investigated whether individuals with UC are more at risk to develop HZ. Hence, the main goal was to compare $\mathrm{HZ}$ incidence in a cohort of patients with an UC and a cohort of patients without any of the UCs under investigation. Exact matching was used to account for differences in the distribution of age and sex between the cohorts. Odds ratios (ORs) were computed and reported on a yearly basis. To identify the marginal effect of each UC, two different strategies were used. The main analysis used data from all patients and accounted for multi-morbidity using a logistic regression model with incident $\mathrm{HZ}$ as the dependent variable and dummies for each UC and age as covariates. Hence, the effect of each UC is quantifiable even if multiple UCs are present in the same patient. A sensitivity analysis was performed using data from patients who had exactly one of the UCs under study.

In the second analysis, the recurrence rates of $\mathrm{HZ}$ in patients with and without UCs were estimated.

A cohort of patients who were initially identified to have an acute HZ in 2008 were followed, and any additional episodes of acute $\mathrm{HZ}$ in at least two quarters of a year following the initial diagnosis were counted. The patients were followed up until leaving SHI, death, or until the end of 2018. Leaving SHI and death resulted in censored observations. The data were used to compute the cumulative probability of experiencing $\mathrm{HZ}$ recurrences, as well as the mean time to recurrence.

\section{Database}

Analyses were based on claims data from one of the largest German SHI, BARMER, and cover the time period 2007-2018. ${ }^{2}$ The BARMER "Wissenschaftliches Data-Warehouse" (W-DWH) accounts for approximately 9 million people, or $13 \%$ of the SHI population in Germany, and is managed with utmost respect to data cleaning and quality by BARMER. The SHI population represents about $87 \%$ of the population living in Germany [12]. Based on comparison with published data from KM6 statistics, the data set is representative of the German SHI population in terms of age and gender distribution [23]. Diagnostic data include all diagnoses documented during physician outpatient contacts

\footnotetext{
2 Please note that results are computed from 2008-2018, but data from 2007 are needed to rule out prior HZ diagnoses for 2008 .
} 
and patient hospital stays. Laboratory or clinical parameters were not included. A general description of the claim database in the German setting can be found in Swart et al. [24].

\section{Study Population}

For all analyses, patients aged 18 years or older in the year under study were included. Not included were patients who were originally insured with Deutsche BKK (approx. 10\% of all current BARMER insured), a SHI which merged with BARMER in 2017, because there were insufficient data on those patients for analysis. For privacy reasons, the W-DWH only provides the year of birth and, hence, age was computed as the difference between the year under study and the year of birth. Based on the structure of (potential) German disease management programs (DMPs) $[25,26]$ and in consultation with a medical expert panel, the following UCs with the corresponding International Classification of Diseases (ICD), Tenth Revision, German Modification (ICD-10-GM) diagnosis codes were defined as potential risks: asthma (code J45), chronic heart failure (CHF; code I50), COPD (codes J44, J96), coronary heart disease (CHD; codes I20, I21, I22, I25), diabetes mellitus type 1 (DMT1; code E10), diabetes mellitus type 2 (DMT2; code E11), depression (code F32, F33, F34), and RA (codes M05, M06).

An individual was identified as belonging to a potential group with an UC if an established diagnois was documented for either an inpatient or an outpatient in two of the four quarters of a study year. A patient could belong to multiple UC groups. For incidence analyses, the UC needed to be present in the year under consideration. In addition, only patients who were observable (i.e., insured) in all four quarters of the year under study were included, which excludes patients who died or left SHI in that year. For estimating recurrence, the UC needed to be present in the year of the initial $\mathrm{HZ}$ diagnosis.

A HZ case was defined as at least one diagnosis of ICD-10-GM code B02 in either an in- or outpatient setting in the year under study, and a corresponding prescription of an antiviral drug
(Anatomical Therapeutic Chemical [ATC] codes: D06BB03, J05AB11, J05AB09, J05AB15, J05AB01, S01AD07, S01AD03). As diagnosis is only reported on a quarterly basis, a case is only counted when the prescription is given in the same quarter. For the analysis of HZ recurrence, ICD code B02.2 (PHN) was excluded to focus only on acute recurrences. The time to recurrence was measured in quarters of a year.

\section{Statistical Analysis}

\section{Incidence}

In the analysis, a patient with an UC was matched to one person of the same age and sex without any of the UCs under study. All individuals aged 100 years and older were combined into one group. In the matched sample, incident cases were counted as the number of patients with at least one established out- or inpatient diagnosis of HZ based on ICD-10-GM criteria (code B02), antiviral medication in the same quarter of a given year, and no such diagnosis in the previous years. ${ }^{3}$ Logistic regression was used to estimate the adjusted ORs for HZ based on the matched sample. As explanatory variables, a dummy variable for each UC was included, which highlights whether the individual was diagnosed with the respective UC, alongside the age of the individual. The latter covariate was included to account for potential difference in age between the cohorts. Adjusted ORs and corresponding confidence intervals for each UC were computed using the exponential transformation of the respective coefficient. The results are reported in accordance with the Robert Koch Institute, the National Institute for Public Health in Germany, for three age groups (18-49 years, $50-59$ years, and 60 years and older) [27]. Based on the recommendation of the medical expert panel, subgroup analyses were also performed for individuals with COPD or asthma as UC, with or without the prescription of at least one systemic corticosteroid co-

\footnotetext{
3 Note that for 2008, only 2007 was considered as previous year. For 2009, 2007 and 2008 are considered, and so on.
} 
medication (ATC: H02A, H02B and R01AD) in the year under study.

All analyses were performed using the glm function in $\mathrm{R}$ (version 3.6.2) [28]. In the sensitivity analysis, 1:3 matching was used because the exclusion of patients with multi-morbidity led to the availability of sufficient controls. The matching proportion was chosen to ensure that the distribution of age and sex was the same within the cohorts. The ORs were computed for each UC. Finally, the 95\% CI were computed using Woolf's method to check the statistical significance of the results [29].

\section{Recurrence}

The analysis of recurrence includes patients who had an incident HZ diagnosis in 2008. Incident cases were defined as patients with no HZ diagnosis in 2007. Also, only patients who did not die in 2008 were included. A recurrent case was defined as a patient with an acute HZ (see above) in at least two quarters of a year after the initial diagnosis. A second recurrence was defined as any new $\mathrm{HZ}$ diagnosis within at least two quarters after the first recurrent diagnosis. All recurrent events were counted, but only the time-to-event for the first and the second recurrent events was used to compute the cumulative $\mathrm{HZ}$ recurrence probabilities by using the Kaplan-Meier estimator [30], reported separately for patients with and without UC, as well as for the different age groups. The analysis was performed using the $\mathrm{R}$ package survival (version 3.1-8) [31, 32].

\section{RESULTS}

\section{Incidence of $\mathrm{HZ}$ in a Population with and Without UCs}

The sizes of the cohorts for each year are shown in Table 1. Beginning with the adult population covered in the SHI, which is larger than 7 million for each year, all patients with UCs were identified. The number of patients with UCs ranged from 1.8 million in 2008 to 2.3 million in 2018. These patients were matched to controls without UCs. The average age of the cohort with an UC was 63 years, while the average age of the cohort without an UC was 61 years. An almost perfect balance was achieved in terms of the sex ratio, with each cohort comprising approximately $63 \%$ females over the total observational period. There is a slight increase in the average number of UCs under study per patient from 2008 to 2018, increasing from 1.4 in 2008 to 1.5 in 2018. The incidence of $\mathrm{HZ}$ in the data varies across age groups, with a higher incidence observed for older populations. The incidences are stable over time, but there is a positive shift in incidences for the cohort with UC when compared to the controls (see also Electronic Supplementary Material [ESM] Table S5). Based on the most recent data from 2018, an incidence of 3.9 per 1000 PY was observed for the age group 18-49 years if no UCs were present but for patients with UCs the incidence was 5.3 per $1000 \mathrm{PY}$; for the age group 50-59 years, the incidences were 5.4 and 7.1 per 1000 PY, respectively. In the oldest age group, comprising persons aged 60 years or older, the incidence was 8.2 per $1000 \mathrm{PY}$ for those without UCs and 9.7 per 1000 PY for the cohort with UCs.

The main results of the analysis are shown in Fig. 1, which presents the OR estimates for each UC for the three age groups: 18-49 years, $50-59$ years, and 60 years and older. The boxplots show the variability in the 11 OR estimates within each age group, one for each year under study. The ORs for most UCs are significantly higher than 1 in each year, and the variation in OR estimates over the years is small (ESM Tables S1-S4). It can be seen that RA has the highest OR, around 1.5, for most years. Excluding diabetes and CHF, the other conditions (i.e., asthma, COPD, CHD, and depression) have ORs falling in the range 1.1-1.3 for most years, which translates into a 10-30\% increase in the odds of an acute $\mathrm{HZ}$ when compared to a person with none of these UCs (ESM Table S1). For both types of diabetes (DMT1, DMT2), ORs $>1$ were observed in the youngest age group (18-49 years) (ESM Table S2). Additionally, for all UCs, the OR is highest in the youngest age group (Fig. 1; ESM Tables S2-S4).

In the subgroup analysis, asthma and COPD patients were stratified according to those with 


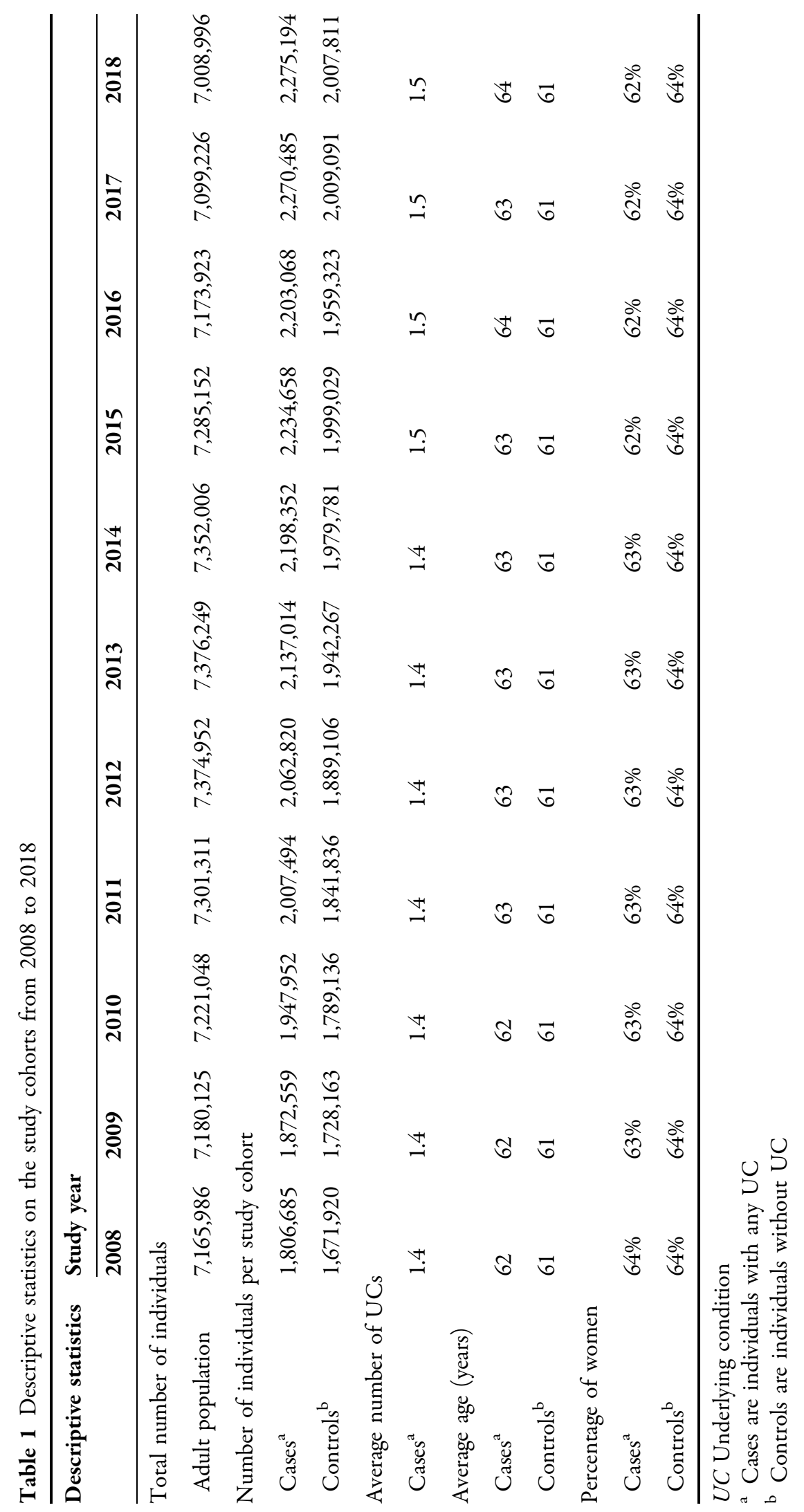




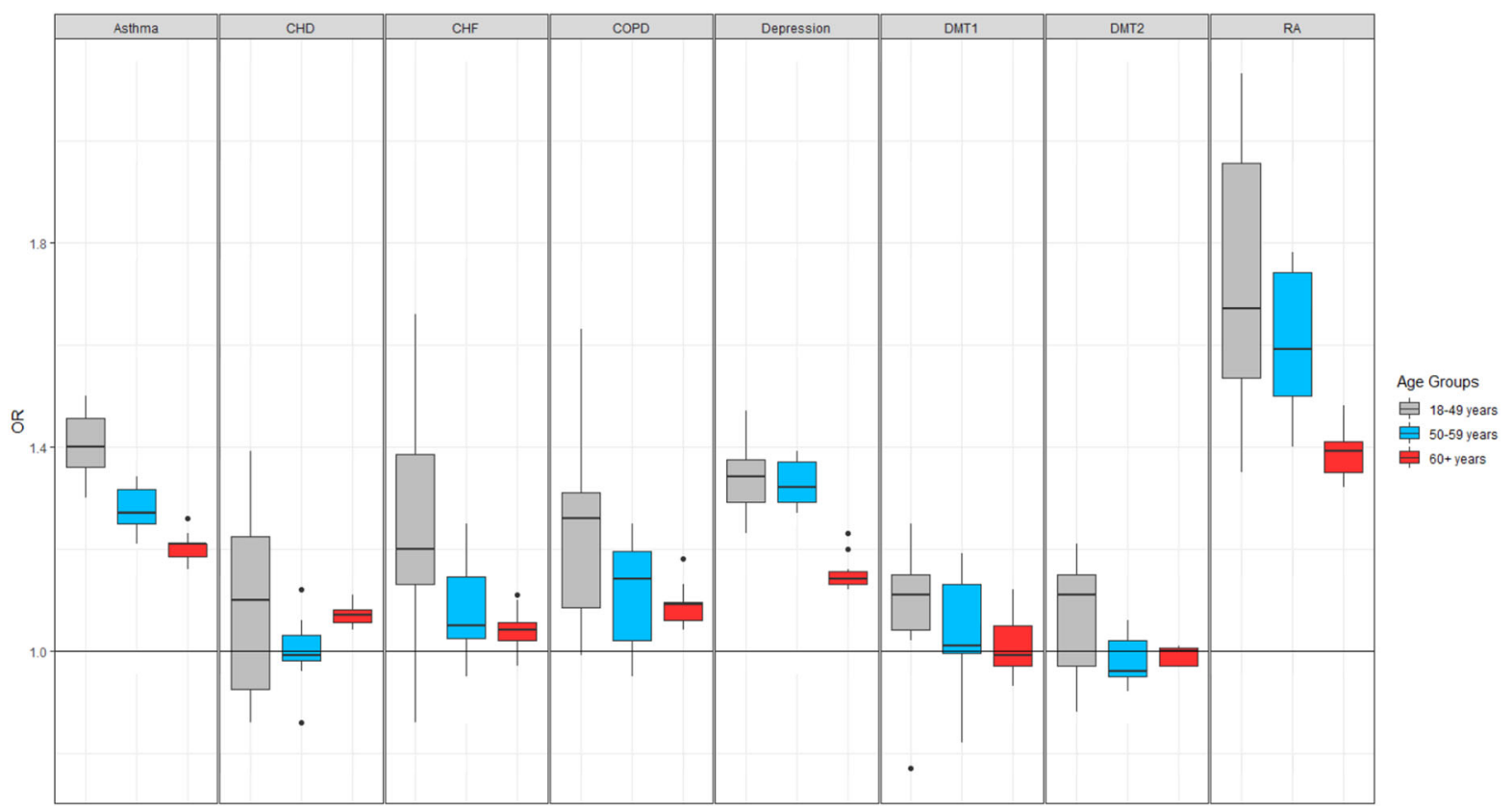

Fig. 1 Boxplot of adjusted ORs of herpes zoster (HZ) in patients with underlying conditions (UCs) from 2008 to 2018. CHD Coronary heart disease, $C H F$ chronic heart

no prescription or those with a prescription of at least one systemic corticosteroid throughout the year under study. The results of this analysis highlight that asthma patients who receive systemic corticosteroid medication had a higher $\mathrm{HZ}$ risk than patients who do not receive the medication. We observed the same effect for COPD patients in the older age groups, but not for patients aged 49 years and younger (Fig. 2).

We repeated the analysis for patients with exactly one UC, which resulted in a smaller sample size and cohorts that were, on average, younger than those in the main analysis. The results are shown in Fig. 3 for the whole population (aged 18 years and older). While the ORs are, on average, higher than in the main analysis, RA, asthma, and depression remain the conditions with the highest ORs. With the exceptions of DMT1, DMT2, and CHF, the ORs for all UCs were significantly higher than 1 for each study year. failure, $C O P D$ chronic obstructive pulmonary disease, $D M T 1$ diabetes mellitus type $1, D M T 2$ diabetes mellitus type 2, $O R$ odds ratio, $R A$ rheumatoid arthritis

\section{HZ Recurrence in a Population with and Without an UC}

In this study, 43,003 patients met the inclusion criteria for the analysis of $\mathrm{HZ}$ recurrence (i.e., incident HZ diagnosis in 2008), of whom 9.6\% $(n=4141)$ were observed to have at least one case of recurrent HZ from 2009 to 2018. Of these 4141 patients, $25 \%(n=1030)$ experienced at least a second recurrence during this time period. As shown in Fig. 4, $0.6-1.2 \%$ of all patients experienced more than two recurrences, depending on their age. The observed mean time to first recurrence was 4.7 years.

The resulting estimates of the cumulative $\mathrm{HZ}$ recurrence curves are shown in Fig. 5. The patient group with the highest risk of recurrence is that comprising patients aged less than 50 years old with at least one UC as, on average, more than $15 \%$ of these patients had experienced at least one recurrence at the end of the follow-up period; the group of patients aged 50-59 years had the second highest risk of recurrence, regardless of UC status. The group 


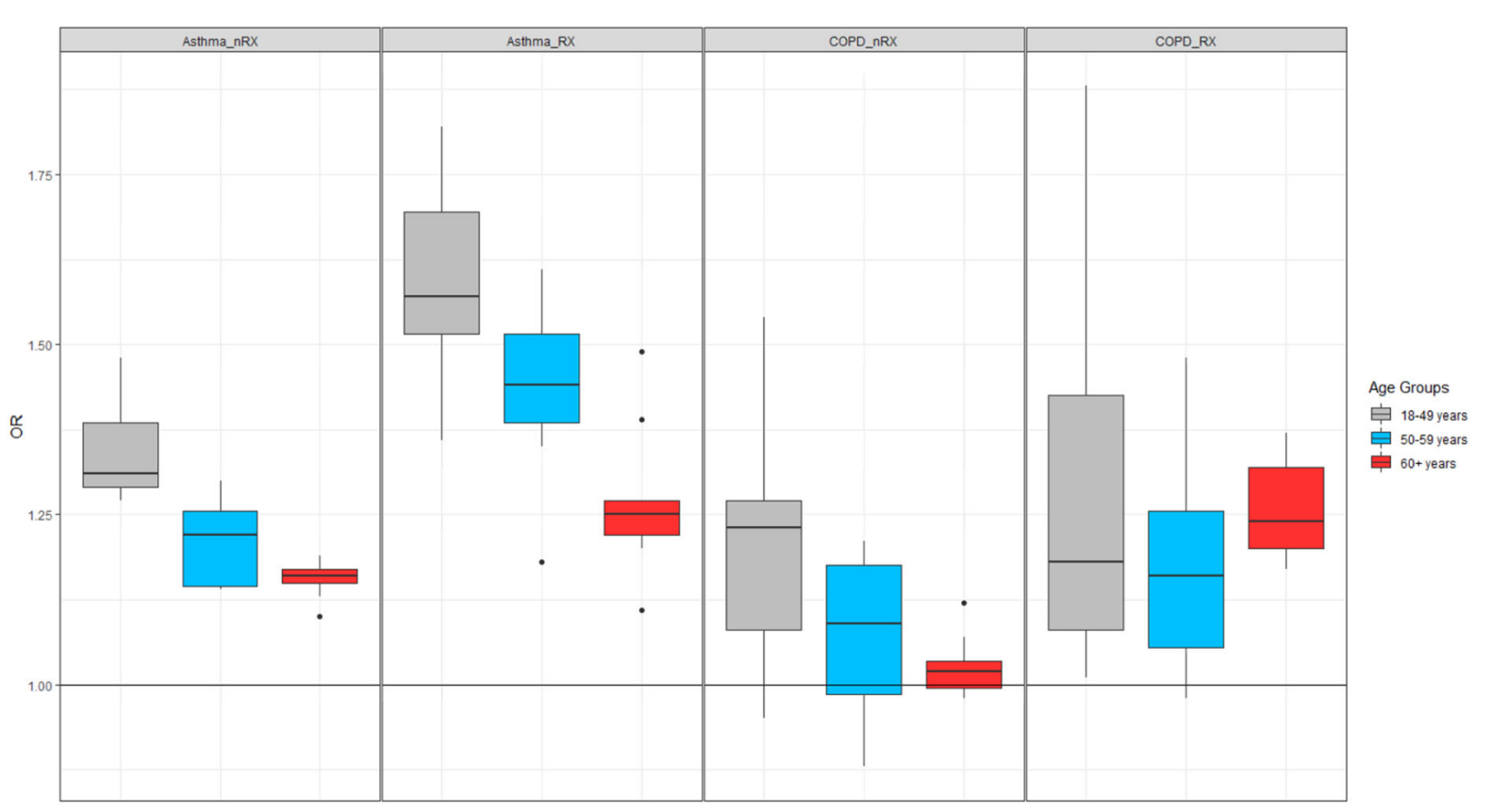

Fig. 2 Boxplot of adjusted ORs of HZ for patients with asthma or COPD with or without systemic corticosteroid treatment from 2008 to 2018. $n R X$ Without medication, $R X$ with medication

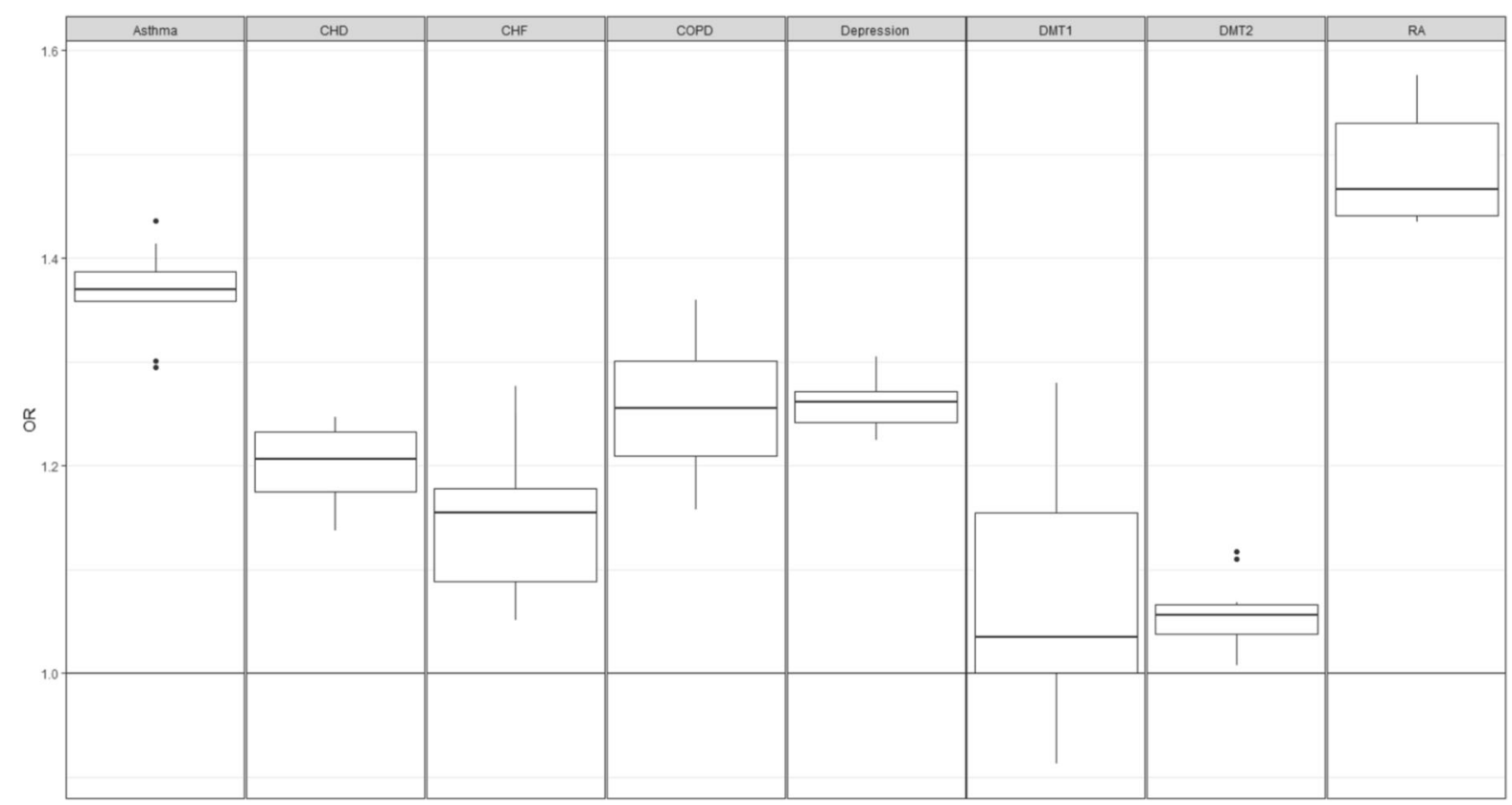

Fig. 3 Boxplot of ORs of the sensitivity analysis cohort from 2008 to 2018

with the lowest risk of recurrence comprised patients aged 60 years and older, whose cumulative probability of recurrence was between 5 and $10 \%$. 


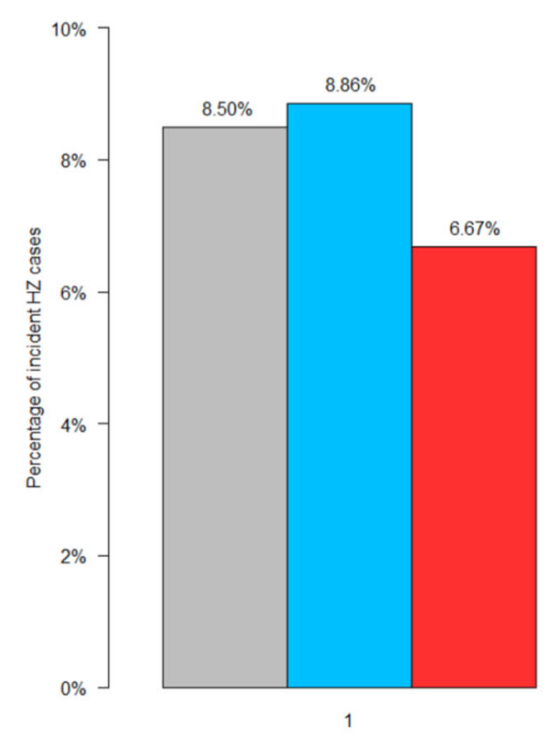

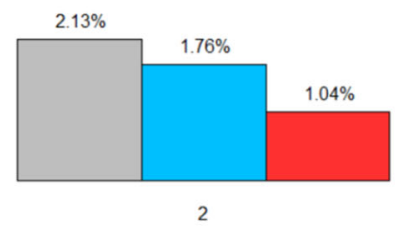

Number of recurrences per patient $\square$ under 50 years

$60+$ years

Fig. 4 Number of recurrences per patient from 2008 to 2010 as a percentage of initial HZ cases according to age group

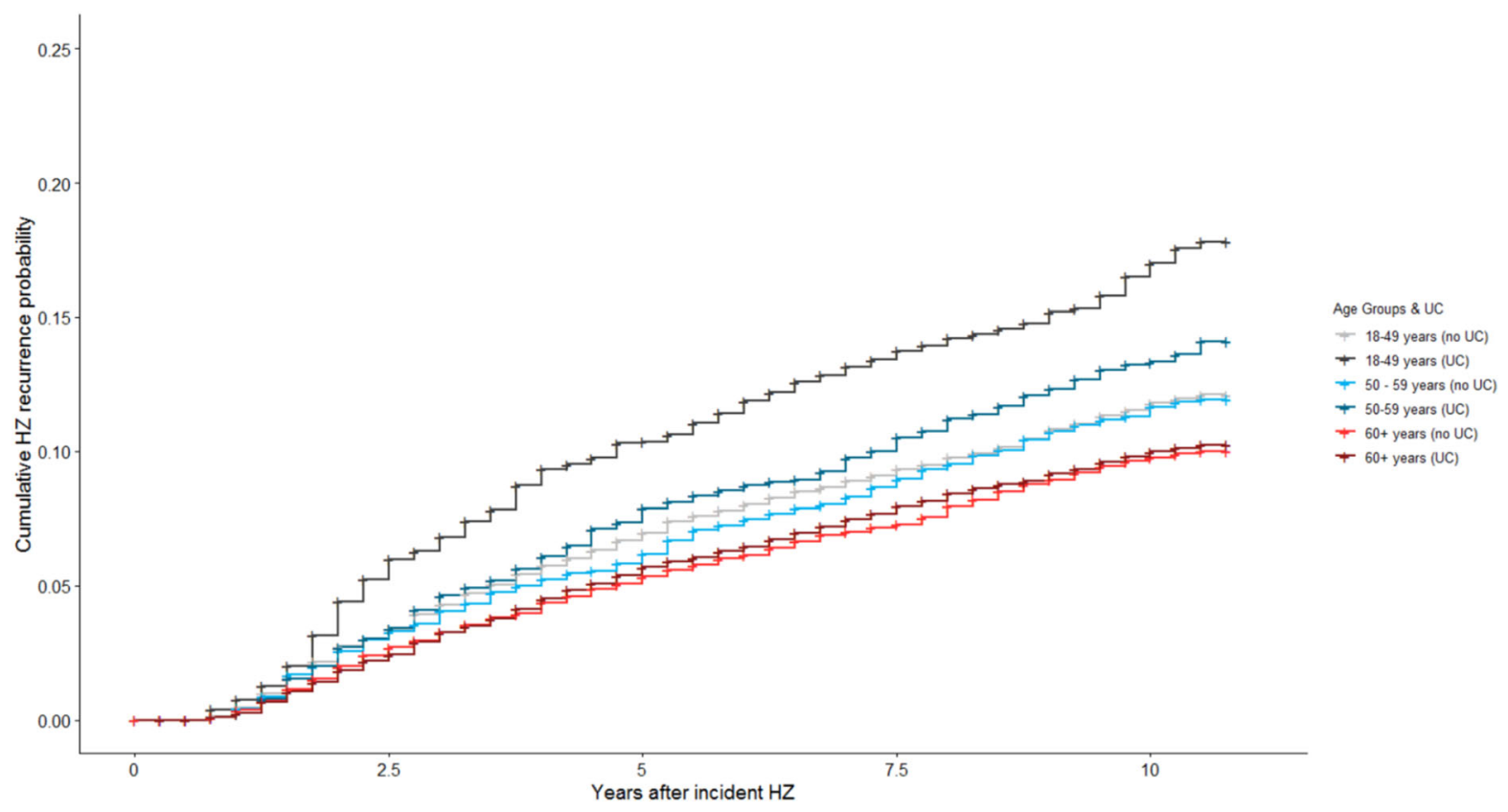

Fig. 5 Cumulative probability for first $\mathrm{HZ}$ recurrence. Steps reflect quarterly data

In addition, the risk of experiencing a second $\mathrm{HZ}$ recurrence was higher than the risk of an initial recurrence (Fig. 6). For the incident HZ, patients aged less than 50 years who had already experienced one recurrence had a $40 \%$ probability of experiencing another recurrence. 


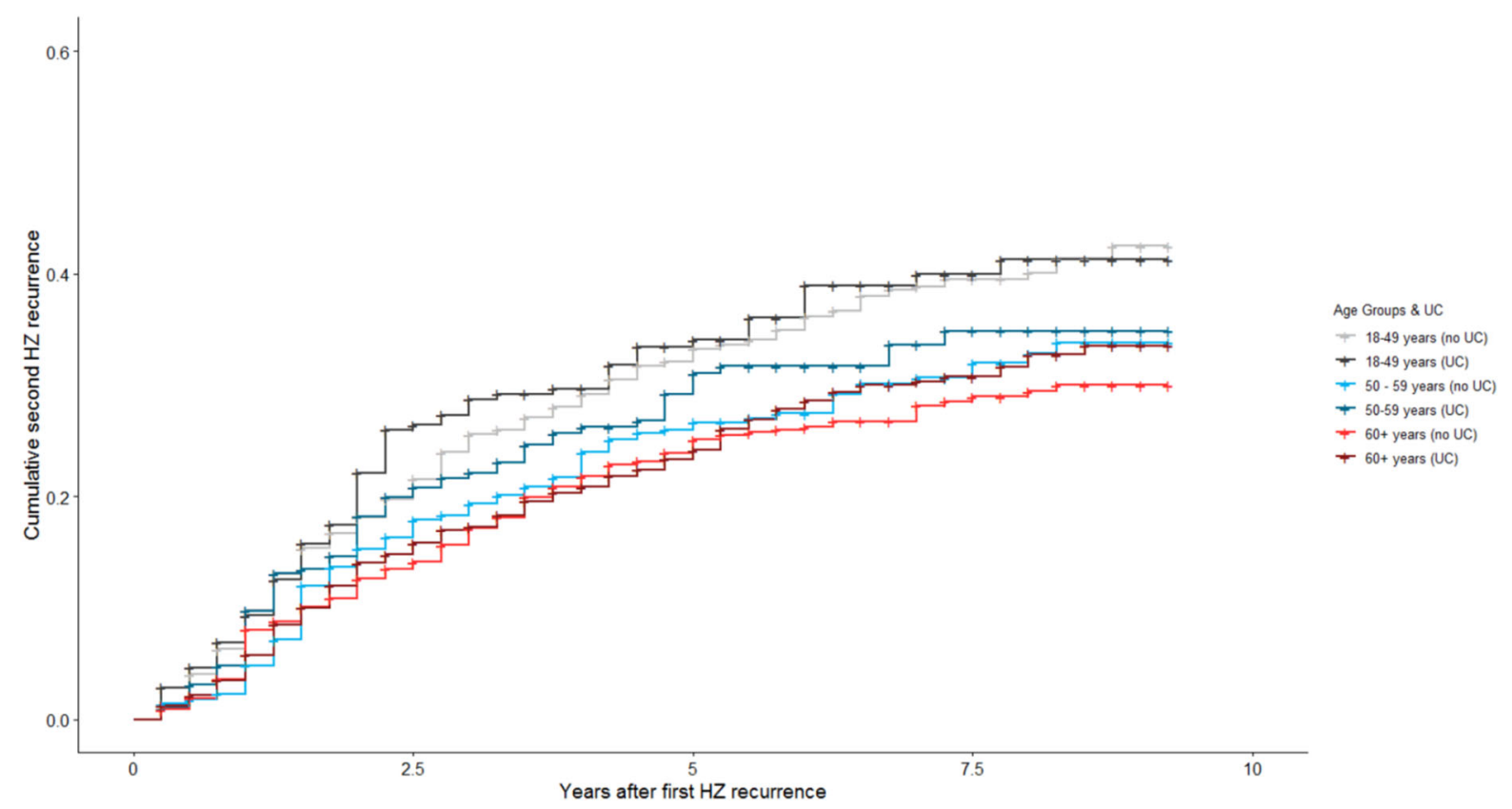

Fig. 6 Cumulative probability for second HZ recurrence after the first recurrence. Steps reflect quarterly data

\section{DISCUSSION}

\section{Study Results in Context of Previous Findings}

Using German claims data, we have conducted an analysis of patients with $\mathrm{HZ}$ and assessed their risk for a recurrence in relation to UCs. The results indicate that patients with either asthma, CHD, COPD, depression, or RA had an increased risk of developing an acute HZ compared to patients without any of the UCs under study. RA had the highest OR among these conditions, varying from 1.37 to 1.57 for all age groups, and patients with depression also showed a significantly higher risk of developing $\mathrm{HZ}$ in all age groups. When the data were adjusted for systemic corticosteroid therapy in patients with asthma and COPD, the risk for an acute $\mathrm{HZ}$ was higher in those using systemic corticosteroid than in those who were not. Analysis of recurrence indicated that patients with at least one UC in the age groups 18-49 years and 50-59 years had the highest risk for a recurrent HZ. Regardless of age groups, the risk of developing a second recurrence was two- to threefold higher as compared to the risk of developing a first recurrence.

Multiple studies have related UCs to an increased risk of $\mathrm{HZ}[13,16,17,33-47]$. In addition, a recent meta-analysis showed robust associations between HZ and UCs across 88 studies [48]. The present study corroborates these results. The related risk for $\mathrm{HZ}$ can be explained by the diseases themselves and their underlying biological mechanisms, as well as by specific immunosuppressive drug treatment.

Our results on the effect of $\mathrm{RA}$ on $\mathrm{HZ}$ are consistent with those reported from other studies. A case-control study from the UK using primary clinical practice data reported an OR very similar to the results of the present study (OR 1.46) [13]. In RA, it is not only the general impairment of the immune system that is associated with an increased risk for infectious diseases, but the disease activity of RA itself plays an important role in the risk of contracting an infectious disease [49]. There is a high prevalence of multi-morbidity, such as depression, asthma, and/or COPD, in patients with RA, which can further impair the immune system [50]. Immunosuppressive medications, such as corticosteroids, azathioprine, 
cyclophosphamide, or tumor necrosis factor inhibitors, which are used for the treatment of RA, are also associated with an increased risk of infections $[35,49]$. This latter association has been investigated for $\mathrm{HZ}$ in an earlier study, which reported that the highest risk for $\mathrm{HZ}$ infections was associated with former cyclophosphamide use (OR 3.17) [51].

Numerous international studies have investigated whether diabetes mellitus is a risk factor for HZ. In accordance with the results presented here, several studies have shown that younger patients with diabetes appear to have an increased risk of $\mathrm{HZ}$ when compared to older patients with diabetes $[13,39,41,43]$. For example, Forbes et al. found that those with the strongest association between HZ and DMT1 (OR 1.51) and HZ and DMT2 (OR 1.22) were those aged less than 50 years [13]. A number of studies have examined the association between HZ and diabetes and shown contradictory results $[16,18,41]$. The varying risk for $\mathrm{HZ}$ across studies can be due to different methodological aspects (i.e., the underlying definition of age groups for patients younger than 50 years, or adjustments for age and comorbidities); for example, one study showed that diabetes patients with high glycated hemoglobin (HbA1c) and aged less than 45 years have an increased risk for HZ [43]. However, laboratory data are usually only available in primary data studies.

The observation of increased risk for $\mathrm{HZ}$ in patients with depression is consistent with results reported in international literature, as reported in a recent meta-analysis (relative risk 1.23) [48]. A retrospective case-control study based on UK primary care data showed that patients with depression younger than 50 years are at a higher risk for developing $\mathrm{HZ}$ (OR 1.24) [13]. Two other studies also observed an increased risk in patients with depression, but did not include different age groups in their analysis $[34,45]$. Although there seems to be an association between depression and risk of $\mathrm{HZ}$, the explanation still remains unclear. It is possible that there is a decreased and dysregulated cell-mediated immunity in patients with depression, as it has been shown that depression is associated with reduced lymphocyte proliferation and decreased proportions of lymphocytes and T-cells [44]. Irwin et al. support this association by showing that VZVspecific responder cell frequency, a marker for cell-mediated immunity, is especially reduced in older patients with major depressive disorders [52, 53]. The observed association for younger age groups and their cell-mediated immunity as well as their specific risk for $\mathrm{HZ}$ requires further research.

The data show that COPD and asthma patients had a significantly higher risk of $\mathrm{HZ}$ when using systemic corticosteroids. The increased risk for $\mathrm{HZ}$ in these patients may be explained by the immunosuppressive effect of corticosteroids, resulting in COPD and asthma patients being susceptible to infectious diseases. Systemic corticosteroids are associated with negative effects on immunity, including the inhibition of inflammatory cytokines, reduction of antigen-presenting cells, and decrease of T-cells [33], consequently increasing the susceptibility to infections.

Recurrence rates for HZ have been previously reported by other authors, yet differences in study designs, study populations, and length of follow-up makes it difficult to compare results $[18,19,54-57]$. Furthermore, there are no other studies reporting the risk for a second recurrence or recurrence for patients with UCs. However, a recent study from Spain reported significantly higher recurrence rates in immunocompromised patients [58]. This result is in line with the results presented here which show that patients with UCs have a higher risk of recurrence. Kim et al. reported overall recurrence rates of 12.0 per $1000 \mathrm{PY}$ [18], and Tseng et al. reported a 10-year cumulative recurrence rate of $10.26 \%$ [54]. Similar to the results in this study, these authors observed a higher probability of recurrence in younger age groups compared to older adults. In the present study, this effect is even more pronounced in patients with at least one UC.

\section{Limitations}

The study presented here has a number of limitations. It must be considered that the 
underlying data are collected for billing purposes. In the literature, the potential for upcoding is discussed for some of the considered UCs [59] and, therefore, it is possible that the risk of $\mathrm{HZ}$ in patients with UC is overestimated. An increased likelihood of receiving a diagnosis of $\mathrm{HZ}$, for example, might result from regular visits to a general practitioner for a chronic condition. It is reasonable to assume that most patients with $\mathrm{HZ}$ would make an appointment with their general practitioner owing to the extensive rash and considerable pain associated with $\mathrm{HZ}$, and also because everyone living in Germany has healthcare insurance. Furthermore, laboratory confirmation is missing and, therefore, other diagnoses cannot be ruled out, mainly zosteriform herpes simplex, which is especially relevant for recurrent $\mathrm{HZ}$ as it is associated with milder clinical symptoms than primary HZ [19]. Also, a number of risk-modifying factors for $\mathrm{HZ}$ incidence, such as the Hb1Ac value or other morbidityassociated laboratory parameters, cannot be captured in the claims database. Another limitation of the study is that it was not possible to adjust the data for some factors that may have affected the prevalence of considered UCs, including smoking, alcohol consumption, physical activity, and dietary habits. In addition to clinical aspects of risk-modifying factors, UC may also adversely impact the QoL in patients suffering from HZ. However, effects on QoL could not be assessed in the present study based on the available data. As the database is limited to one SHI and individuals in Germany self-select their SHI, it is important to assess the representativeness of the database. A comparison with national population statistics shows that those insured by BARMER are representative in terms of age and gender, as confirmed by national health technology assessment institutions [60].

\section{Implications for Health Policy and Further Research}

The standard use of a vaccine for the prevention of $\mathrm{HZ}$ has recently been recommended by the German Standing Committee on Vaccination
(STIKO) in immunocompetent adults older than 60 years and for adults older than 50 years with increased health risks due to an UC (e.g., human immunodeficiency virus, RA, lupus, COPD, asthma, and diabetes) [27]. ${ }^{4}$ There is no vaccination recommendation for patients with depression under the age of 60 years, who were identified as having a significantly increased HZ risk. The results of this study could be incorporated into national treatment guidelines and structured DMPs to support optimal treatment and higher vaccination coverage in populations with UC. Considering the differing results in the literature, further research is needed on the observed risk in persons with diabetes. For this purpose, data from DMPs would be useful as clinical and laboratory variables are recorded there. Additionally, the underlying pathogenetic mechanism for the observed risks in underlying depression need further investigation. In addition to the inclusion of clinical parameters, the differentiation of other age groups can also provide information on specific risk constellations.

\section{CONCLUSION}

The study shows, for the first time, a higher risk for HZ in patients with an UC in Germany and a higher risk for recurrence in younger age groups. This is the first analysis on the incidence and recurrence of $\mathrm{HZ}$ for populations with UCs in the German healthcare setting. The results from the present study confirm the higher incidence of HZ in German patients with certain UCs, as previously reported in the international context. The analysis provides important information for updating national health care guideline (DMPs), which are intended to support a structured treatment of some of the risk groups under consideration. Since the data are generalizable to the population living in Germany, this could, for example, provide relevant information about if and when

\footnotetext{
4 Note that the vaccine has been recommended in Germany since March of 2018. However, due to its low availability and in turn low uptake in 2018, we are confident that the introduction of the vaccine had no influence on the results presented in this paper.
} 
people who already experienced $\mathrm{HZ}$ should be vaccinated against $H Z$.

\section{ACKNOWLEDGMENTS}

Funding. GlaxoSmithKline Biologicals SA funded this study (GSK study identifier: HO-1919881) and was involved in the development of the data analysis strategy but neither had access to the database nor conducted the data analysis. GlaxoSmithKline Biologicals SA also took in charge all costs associated with the development of this manuscript and the Journal's rapid service fee.

Disclosures. Magdalena Schwarz and Amit Bhavsar are employees of the GSK group of companies. Bernhard Ultsch and Johannes Hain are employed by and hold shares in the GSK group of companies. Klaus Wahle reports personal fees from the GSK group of companies for advisory boards outside the submitted work. Peter Wutzler, Carl-Peter Criée, Christiane Hermann, Klaus Wahle, and Martin Füchtenbusch report personal fees from the GSK group of companies for advisory boards during the conduct of the study. Magdalena Schwarz, Johannes Hain, Bernhard Ultsch, Amit Bhavsar, Peter Wutzler, Carl-Peter Criée, Christiane Hermann, Klaus Wahle, and Martin Füchtenbusch declare no other financial and non-financial relationships and activities. Manuel Batram, Julian Witte, Maren Steinmann, and Wolfgang Greiner declare no financial and non-financial relationships and activities and no conflicts of interest.

Compliance with Ethics Guidelines. This study has been conducted in accordance with applicable subject privacy requirements and the guiding principles of the Declaration of Helsinki of 1964. In line with the national guidelines "Good Practice Secondary Data Analysis" [21] as well as the STROSA standard for "Standardized Reporting of Secondary data Analyses" [22], consultation of an ethics committee was not required for analyses based exclusively on secondary data.
In accordance with \$75 SGB X (Section 75Book 10 of the Social Code [SGB X] of Germany) on social administration procedures and social data protection, informed consent of the insurant was not required. Since the study was based on routinely collected pseudonymized data and persons were not contacted, ethical approval was not needed.

Medical Writing, Editorial, and Other Assistance. The authors thank Desmond Curran and Ahmed Salem (GSK) for their comments regarding the results, Sandra Lindenberg (GSK) for her involvement in the study conduct and her comments on the preliminary results, and Laura Wallisch (GSK) for administrative support. The authors would also like to thank Business and Decision Life Sciences platform for editorial assistance and manuscript coordination, on behalf of GSK. Aurélie Roth and Elena Chaves Rodriguez coordinated manuscript development and editorial support.

Authorship. All named authors meet the International Committee of Medical Journal Editors (ICMJE) criteria for authorship for this article, take responsibility for the integrity of the work as a whole, and have given their approval for this version to be published.

Data availability. The datasets analyzed during the current study are not publicly available due to German social security and privacy laws.

Open Access. This article is licensed under a Creative Commons Attribution-NonCommercial 4.0 International License, which permits any non-commercial use, sharing, adaptation, distribution and reproduction in any medium or format, as long as you give appropriate credit to the original author(s) and the source, provide a link to the Creative Commons licence, and indicate if changes were made. The images or other third party material in this article are included in the article's Creative Commons licence, unless indicated otherwise in a credit line to the material. If material is not included in the article's Creative Commons licence and your intended use is not permitted by statutory 
regulation or exceeds the permitted use, you will need to obtain permission directly from the copyright holder. To view a copy of this licence, visit http://creativecommons.org/licenses/by$\mathrm{nc} / 4.0 /$.

\section{REFERENCES}

1. Gnann JW, Whitley RJ. Clinical practice. Herpes zoster. N Engl J Med. 2002;347(5):340-6. https:// doi.org/10.1056/NEJMcp013211.

2. Sampathkumar P, Drage LA, Martin DP. Herpes zoster (shingles) and postherpetic neuralgia. Mayo Clin Proc. 2009;84(3):274-80. https://doi.org/10. 1016/S0025-6196(11)61146-4.

3. Werner RN, Nikkels AF, Marinović B, et al. European consensus-based (S2k) Guideline on the Management of Herpes Zoster-guided by the European Dermatology Forum (EDF) in cooperation with the European Academy of Dermatology and Venereology (EADV), Part 1: Diagnosis. J Eur Acad Dermatol Venereol. 2017;31(1):9-19. https://doi. org/10.1111/jdv.13995.

4. Werner RN, Nikkels AF, Marinović B, et al. European consensus-based (S2k) Guideline on the Management of Herpes Zoster-guided by the European Dermatology Forum (EDF) in cooperation with the European Academy of Dermatology and Venereology (EADV), Part 2: Treatment. J Eur Acad Dermatol Venereol. 2017;31(1):20-9. https://doi. org/10.1111/jdv.13957.

5. Gauthier A, Breuer J, Carrington D, Martin M, Rémy V. Epidemiology and cost of herpes zoster and postherpetic neuralgia in the United Kingdom. Epidemiol Infect. 2009;137(1):38-47. https://doi.org/ $10.1017 /$ S0950268808000678.

6. Katz J, Cooper EM, Walther RR, Sweeney EW, Dworkin RH. Acute pain in Herpes Zoster and its impact on health-related quality of life. Clin Infect Dis. 2004;39(3):342-8. https://doi.org/10.1086/ 421942.

7. Wutzler P. Herpes zoster und postherpetische Neuralgie-Vorbeugung durch Impfung? Dtsch Med Wochenschr. 2009;134(Suppl 2):S90-4. https://doi. org/10.1055/s-0029-1220217.

8. Curran D, Schmidt-Ott R, Schutter U, Simon J, Anastassopoulou A, Matthews S. Impact of herpes zoster and postherpetic neuralgia on the quality of life of Germans aged 50 or above. BMC Infect Dis.
2018;18(1):496. https://doi.org/10.1186/s12879018-3395-Z.

9. Ultsch B, Köster I, Reinhold T, et al. Epidemiology and cost of herpes zoster and postherpetic neuralgia in Germany. Eur J Health Econ. 2013;14(6): 1015-26. https://doi.org/10.1007/s10198-0120452-1.

10. Hillebrand $\mathrm{K}$, Bricout $\mathrm{H}$, Schulze-Rath $\mathrm{R}$, Schink T, Garbe E. Incidence of herpes zoster and its complications in Germany, 2005-2009. J Infect. 2015;70(2):178-86. https://doi.org/10.1016/j.jinf. 2014.08.018.

11. Caputo M, Horn J, Karch A, et al. Herpes zoster incidence in Germany-an indirect validation study for self-reported disease data from pretest studies of the population-based German National Cohort. BMC Infect Dis. 2019;19(1):99. https://doi. org/10.1186/s12879-019-3691-2.

12. Busse $\mathrm{R}$, Blümel $\mathrm{M}$, Knieps $\mathrm{F}$, Bärnighausen $\mathrm{T}$. Statutory health insurance in Germany: a health system shaped by 135 years of solidarity, self-governance, and competition. Lancet. 2017;390(10097):882-97. https://doi.org/10.1016/ S0140-6736(17)31280-1.

13. Forbes HJ, Bhaskaran K, Thomas SL, Smeeth L, Clayton T, Langan SM. Quantification of risk factors for herpes zoster: population based case-control study. BMJ. 2014;348:g2911. https://doi.org/10. 1136/bmj.g2911.

14. Imafuku S, Dormal G, Goto Y, Jégou C, Rosillon D, Matsuki T. Risk of herpes zoster in the Japanese population with immunocompromising and chronic disease conditions: results from a claims database cohort study, from 2005 to 2014. J Dermatol. 2020;47(3):236-44. https://doi.org/10.1111/ 1346-8138.15214.

15. Esteban-Vasallo MD, Domínguez-Berjón MF, GilPrieto R, Astray-Mochales J, Gil de Miguel Á. Sociodemographic characteristics and chronic medical conditions as risk factors for herpes zoster. Hum Vaccin Immunother 2014; 10(6):1650-60. https://doi.org/10.4161/hv.28620.

16. Guignard AP, Greenberg M, Lu C, Rosillon D, Vannappagari V. Risk of herpes zoster among diabetics: a matched cohort study in a US insurance claim database before introduction of vaccination, 1997-2006. Infection. 2014;42(4):729-35. https:// doi.org/10.1007/s15010-014-0645-X.

17. Muñoz-Quiles C, López-Lacort M, Ampudia-Blasco FJ, Díez-Domingo J. Risk and impact of herpes zoster on patients with diabetes: a population-based study, 2009-2014. Hum Vaccin Immunother. 
2017;13(11):2606-11. https://doi.org/10.1080/ 21645515.2017.1368600.

18. Kim YJ, Lee CN, Lee MS, et al. Recurrence rate of Herpes Zoster and its risk factors: a populationbased cohort study. J Korean Med Sci. 2019;34(2): e1. https://doi.org/10.3346/jkms.2019.34.e1.

19. Nakamura Y, Miyagawa F, Okazaki A, et al. Clinical and immunologic features of recurrent herpes zoster (HZ). J Am Acad Dermatol. 2016;75(5):950-956. e1. https://doi.org/10.1016/j.jaad.2016.05.037.

20. Pierson JC. Reluctance regarding recurrent herpes zoster. J Am Acad Dermatol. 2017;76(4):e143. https://doi.org/10.1016/j.jaad.2016.12.042.

21. Swart E, Gothe H, Geyer S, et al. Gute Praxis Sekundärdatenanalyse (GPS): Leitlinien und Empfehlungen. Gesundheitswesen. 2015;77(2): 120-6. https://doi.org/10.1055/s-0034-1396815.

22. Swart E, Schmitt J. STandardized Reporting Of Secondary data Analyses (STROSA)_-Vorschlag für ein Berichtsformat für Sekundärdatenanalysen. Z Evid Fortbild Qual Gesundhwes. 2014;108(8-9):511-6. https://doi.org/10.1016/j.zefq.2014.08.022.

23. Mitglieder und Versicherte der Gesetzlichen Krankenversicherung (GKV): Statistik über Versicherte, gegliedert nach Status, Alter, Wohnort und Kassenart; 2020. https://www.bundesgesundh eitsministerium.de/themen/krankenversicherung/ zahlen-und-fakten-zur-krankenversicherung/mitgli eder-und-versicherte.html. Accessed 2 Feb 2021.

24. Swart E. Health care utilization research using secondary data. In: Janssen C, Swart E, von Lengerke T, editors. Health care utilization in Germany: theory, methodology, and results. New York: Springer; 2014. p. 63-8.

25. Richtlinie des Gemeinsamen Bundesauschusses zur Zusammenführung der Anforderungen an strukturierte Behandlungsprogramme nach $\S 137 \mathrm{f}$ Absatz 2 SGB V (DMP-Anforderungen-Richtlinie/ DMP-A-RL). https://www.g-ba.de/richtlinien/83/. Accessed 3 Feb 2021.

26. Schang L, Thomson S, Czypionka T. Explaining differences in stakeholder take up of disease management programmes: a comparative analysis of policy implementation in Austria and Germany. Health Policy. 2016;120(3):281-92. https://doi.org/ 10.1016/j.healthpol.2016.02.002.

27. Siedler A, Koch J, Garbe E, et al. Background paper to the decision to recommend the vaccination with the inactivated herpes zoster subunit vaccine: Statement of the German Standing Committee on Vaccination (STIKO) at the Robert Koch Institute. Bundesgesundheitsblatt Gesundheitsforschung
Gesundheitsschutz. 2019;62(3):352-76. https://doi. org/10.1007/s00103-019-02882-5.

28. R Core Team. R: A language and environment for statistical computing; 2019. https://www.R-project. org/. Accessed 11 Oct 2020.

29. Agresti A. Categorical data analysis. 2nd ed. Hoboken: Wiley; 2002.

30. Gail M, Krickeberg K, Samet J, et al. Survival and event history analysis. New York: Springer; 2008.

31. Therneau TM. A package for survival analysis in $\mathrm{R}: \mathrm{R}$ package version 3.2-7; 2020. https://CRAN.Rproject.org/package=survival. Accessed 14 Dec 2020.

32. Therneau TM, Grambsch PM. Modeling survival data: extending the Cox model. 2nd ed. New York: Springer; 2001.

33. Yang Y-W, Chen Y-H, Wang K-H, Wang C-Y, Lin $\mathrm{H}-\mathrm{W}$. Risk of herpes zoster among patients with chronic obstructive pulmonary disease: a population-based study. CMAJ. 2011;183(5):E275-80. https://doi.org/10.1503/cmaj.101137.

34. Joesoef RM, Harpaz R, Leung J, Bialek SR. Chronic medical conditions as risk factors for herpes zoster. Mayo Clin Proc. 2012;87(10):961-7. https://doi. org/10.1016/j.mayocp.2012.05.021.

35. Smitten AL, Choi HK, Hochberg MC, et al. The risk of herpes zoster in patients with rheumatoid arthritis in the United States and the United Kingdom. Arthritis Rheum. 2007;57(8):1431-8. https:// doi.org/10.1002/art.23112.

36. Veetil BMA, Myasoedova E, Matteson EL, Gabriel $\mathrm{SE}$, Green $\mathrm{AB}$, Crowson CS. Incidence and time trends of herpes zoster in rheumatoid arthritis: a population-based cohort study. Arthritis Care Res (Hoboken). 2013;65(6):854-61. https://doi.org/10. $1002 /$ acr. 21928.

37. Peng Y-H, Fang H-Y, Wu B-R, et al. Adult asthma is associated with an increased risk of herpes zoster: a population-based cohort study. J Asthma. 2017;54(3):250-7. https://doi.org/10.1080/ 02770903.2016 .1211142 .

38. Chen S-J, Huang K-H, Tsai W-C, Lin C-L, Cheng Y-D, Wei C-C. Asthma status is an independent risk factor for herpes zoster in children: a populationbased cohort study. Ann Med. 2017;49(6):504-12. https://doi.org/10.1080/07853890.2017.1309060.

39. Chen H-H, Lin I-C, Chen H-J, Yeh S-Y, Kao C-H. Association of herpes zoster and type 1 diabetes mellitus. PLoS ONE. 2016;11(5):e0155175. https:// doi.org/10.1371/journal.pone.0155175. 
40. Hata A, Kuniyoshi M, Ohkusa Y. Risk of Herpes zoster in patients with underlying diseases: a retrospective hospital-based cohort study. Infection. 2011;39(6):537-44. https://doi.org/10.1007/ s15010-011-0162-0.

41. Lai S-W, Lin C-L, Liao K-F. Real-world database investigating the association between diabetes mellitus and herpes zoster in Taiwan. Medicine (Baltimore) 2019;98(18):e15463.https://doi.org/10. 1097/MD.0000000000015463.

42. Queenan JA, Farahani P, Ehsani-Moghadam B, Birtwhistle RV. The prevalence and risk for herpes zoster infection in adult patients with diabetes mellitus in the Canadian primary care sentinel surveillance network. Can J Diabetes. 2018;42(5): 465-9. https://doi.org/10.1016/j.jcjd.2017.10.060.

43. Heymann AD, Chodick G, Karpati T, et al. Diabetes as a risk factor for herpes zoster infection: results of a population-based study in Israel. Infection. 2008;36(3):226-30. https://doi.org/10.1007/ s15010-007-6347-x.

44. Choi HG, Kim E-J, Lee YK, Kim M. The risk of herpes zoster virus infection in patients with depression: a longitudinal follow-up study using a national sample cohort. Medicine (Baltimore). 2019;98(40):e17430. https://doi.org/10.1097/MD. 0000000000017430 .

45. Lasserre A, Blaizeau F, Gorwood P, et al. Herpes zoster: family history and psychological stress-casecontrol study. J Clin Virol. 2012;55(2):153-7. https://doi.org/10.1016/j.jcv.2012.06.020.

46. Schmidt SAJ, Langan SM, Pedersen HS, et al. Mood disorders and risk of Herpes Zoster in 2 populationbased case-control studies in Denmark and the United Kingdom. Am J Epidemiol. 2018;187(5): 1019-28. https://doi.org/10.1093/aje/kwx338.

47. Wu P-H, Lin Y-T, Lin C-Y, Huang M-Y, Chang W-C, Chang W-P. A nationwide population-based cohort study to identify the correlation between heart failure and the subsequent risk of herpes zoster. BMC Infect Dis. 2015;15:17. https://doi.org/10. 1186/s12879-015-0747-9.

48. Marra F, Parhar K, Huang B, Vadlamudi N. Risk factors for Herpes Zoster infection: a meta-analysis. Open Forum Infect Dis 2020; 7(1): ofaa005. https:// doi.org/10.1093/ofid/ofaa005.

49. Au K, Reed G, Curtis JR, et al. High disease activity is associated with an increased risk of infection in patients with rheumatoid arthritis. Ann Rheum Dis. 2011;70(5):785-91. https://doi.org/10.1136/ard. 2010.128637.
50. Dougados M, Soubrier M, Antunez A, et al. Prevalence of comorbidities in rheumatoid arthritis and evaluation of their monitoring: results of an international, cross-sectional study (COMORA). Ann Rheum Dis. 2014;73(1):62-8. https://doi.org/10. 1136/annrheumdis-2013-204223.

51. Widdifield J, Bernatsky S, Paterson JM, et al. Serious infections in a population-based cohort of 86,039 seniors with rheumatoid arthritis. Arthritis Care Res (Hoboken). 2013;65(3):353-61. https://doi.org/10. 1002/acr.21812.

52. Irwin M, Costlow C, Williams $\mathrm{H}$, et al. Cellular immunity to varicella-zoster virus in patients with major depression. J Infect Dis 1998;178(Supp1): S104-S108. https://doi.org/10.1086/514272.

53. Irwin MR, Levin MJ, Carrillo C, et al. Major depressive disorder and immunity to varicella-zoster virus in the elderly. Brain Behav Immun. 2011;25(4):759-66. https://doi.org/10.1016/j.bbi. 2011.02.001.

54. Tseng HF, Bruxvoort K, Ackerson B, et al. The epidemiology of Herpes Zoster in immunocompetent, unvaccinated adults $\geq 50$ years old: incidence, complications, hospitalization, mortality, and recurrence. J Infect Dis. 2020;222(5):798-806. https://doi.org/10.1093/infdis/jiz652.

55. Shiraki K, Toyama N, Daikoku T, Yajima M. Herpes Zoster and recurrent Herpes Zoster. Open Forum Infect Dis 2017; 4(1): ofx007. https://doi.org/10. 1093/ofid/ofx007.

56. Yawn BP, Wollan PC, Kurland MJ, St Sauver JL, Saddier P. Herpes zoster recurrences more frequent than previously reported. Mayo Clin Proc. 2011;86(2):88-93. https://doi.org/10.4065/mcp. 2010.0618.

57. Qian J, Macartney K, Heywood AE, Sheridan S, Liu B. Risk of recurrent herpes zoster in a populationbased cohort study of older adults. J Am Acad Dermatol. 2020;127(3):314-30. https://doi.org/10. 1016/j.jaad.2020.06.1013.

58. Muñoz-Quiles C, López-Lacort M, Díez-Domingo J, Orrico-Sánchez A. Herpes zoster risk and burden of disease in immunocompromised populations: a population-based study using health system integrated databases, 2009-2014. BMC Infect Dis. 2020;20(1):905. https://doi.org/10.1186/s12879020-05648-6.

59. Erler A. Garbage in Garbage out? Morbiditätsorientierte Regelleistungsvolumina und Validität von Abrechnungsdiagnosen in hausärztlichen Praxen; 2007. https://refubium.fu-berlin.de/handle/fub188/ 7236. Accessed 14 Oct 2020. 
60. Institut für Qualität und Wirtschaftlichkeit im Gesundheitswesen. Nutzung von BARMER-Verdes IQWiG; 2020. https://www.iqwig.de/projekte/ sorgungsdaten im Verfahren der Dossierbewertung ga17-04.html. Accessed 14 Oct 2020. 